\title{
Review
}

\section{Functions of HKT transporters in sodium transport in roots and in protecting leaves from salinity stress}

\author{
Tomoaki Horie ${ }^{1}$, Mitsuo Sugawara $^{2}$, Kiyotaka Okunou², Hideki Nakayama², \\ Julian I. Schroeder ${ }^{3}$, Atsuhiko Shinmyo ${ }^{2}$, Kazuya Yoshida ${ }^{2, *}$ \\ ${ }^{1}$ Group of Molecular and Functional Plant Biology, Research Institute for Bioresources, Okayama University, \\ Kurashiki, Okayama 710-0046, Japan; ${ }^{2}$ Graduate School of Biological Sciences, Nara Institute of Science and \\ Technology, Nara 630-0192, Japan; ${ }^{3}$ Division of Biological Sciences, Cell and Developmental Biology Section, and \\ Center for Molecular Genetics, University of California, San Diego, 9500 Gilman Drive, La Jolla, CA 92093-0116, \\ USA \\ *E-mail: kazz@bs.naist.jp Tel: +81-743-72-5461 Fax: +81-743-72-5469
}

Received December 15, 2007; accepted February 8, 2008 (Edited by K. Hiratsuka)

\begin{abstract}
Excessive sodium $\left(\mathrm{Na}^{+}\right)$accumulation in plants due to soil salinity is toxic to most higher plants including crop plants. Many genes encoding $\mathrm{Na}^{+}$permeable transporters/channels have been identified for the last 15 years, based on genetic approaches, genome-sequencing projects and functional complementation screening using yeast mutants. The HKTtype transporter/channel class is one of the best characterized $\mathrm{Na}^{+}$permeable membrane proteins in plants. Interestingly, most $\mathrm{Na}^{+}$permeable proteins including HKT-type transporters/channels in plants were shown or deduced to play a protective role against salinity stress. $\mathrm{A} \mathrm{Na}^{+}$selective transporter/channel in rice (Oryza sativa), OsHKT2;1, however, has recently been proven to function in "nutritional $\mathrm{Na}^{+}$absorption" in $\mathrm{K}^{+}$-starved roots rather than functioning in a protective role under salinity stress. Here we review findings on the HKT-type transporters/channels, mainly focusing on the function of OsHKT2;1 that is tightly regulated by $\mathrm{K}^{+} / \mathrm{Na}^{+}$homeostatic mechanisms of rice plants. We also discuss functions of Arabidopsis thaliana AtHKT1;1 and rice OsHKT1;5 in protecting plant leaves from over-accumulating toxic $\mathrm{Na}^{+}$ concentrations during salinity stress by removing $\mathrm{Na}^{+}$from the xylem sap.
\end{abstract}

Key words: $\quad \mathrm{K}^{+} / \mathrm{Na}^{+}$transporter, Oryza sativa, Arabidopsis thaliana, P-loop domain, nutritional $\mathrm{Na}^{+}$uptake.

$\mathrm{K}^{+}$is the most abundant cation in plant cells and plays essential roles in osmotic regulation, cell growth, enzyme activity, membrane polarization and salt tolerance. Plants have many kinds of $\mathrm{K}^{+}$transporters and some of them function in the uptake of $\mathrm{K}^{+}$from the soil to cells across plasma membranes (Hirsch et al. 1998; Gierth et al. 2005). A number of cDNAs encoding plant $\mathrm{K}^{+}$ channels and transporters have been isolated and characterized (Sentenac et al. 1992; Anderson et al. 1992; Schachtman and Schroeder, 1994; Santa-Maria et al. 1997; Kim et al. 1998; Fu and Luan, 1998; Fairbairn et al. 2000). Analyses of the TaHKT2;1 (previously named TaHKT1) from wheat (Triticum aestivum) (Platten et al. 2006) were the first reports for the HKTtype transporter/channel in plants (Schachtman and Schroeder 1994; Rubio et al. 1995). TaHKT2;1 has been shown to mediate high affinity $\mathrm{Na}^{+} / \mathrm{K}^{+}$co-transport and low affinity $\mathrm{Na}^{+}$transport at high $\mathrm{Na}^{+}$concentrations in yeast cells and Xenopus laevis oocytes (Rubio et al. 1995; Gassmann et al. 1996). TaHKT2;1 mediates high rates of $\mathrm{Na}^{+}$influx at low and high $\mathrm{Na}^{+}$concentrations (Rubio et al. 1995; Gassmann et al. 1996). These studies indicate a channel-like transport mode of TaHKT2;1 (Gassmann et al. 1996). Subsequently, many cDNA encoding proteins belonging to the HKT family have been cloned from various plants and functional analysis of each HKT is advanced. We summarize here functions of HKT proteins in the $\mathrm{K}^{+}$and $\mathrm{Na}^{+}$transport systems in rice (Oryza sativa) and Arabidopsis thaliana.

\section{Identification of OsHKT2;1 and OsHKT2;2 cDNA, and their ion selectivity in heterologous expression systems}

Complementary DNAs encoding the HKT-type transporter/channel were isolated from two different rice varieties, a salt tolerant variety Pokkali and an intermediate variety Nipponbare, by a homology-based screen using the TaHKT2;1 cDNA as probe in a high stringency condition (Horie et al. 2001). The OsHKT2;1 (previously named $O S H K T 1$ ) cDNA was isolated from both varieties with no amino acid difference in the encoded proteins, while the OsHKT2;2 (previously named Po-OsHKT2) cDNA was found only in the 
rice cultivar, Pokkali (Horie et al. 2001). OsHKT2;2 was found under low $\mathrm{Na}^{+}$concentration to mediate TaHKT2;1-like $\mathrm{Na}^{+} / \mathrm{K}^{+}$co-transport, whereas OsHKT2;1 was found to mediate $\mathrm{Na}^{+}$selective transport in yeast mutants and Xenopus oocytes, despite the fact that OsHKT2;1 and OsHKT2;2 are highly homologous sharing more than $91 \%$ identity at the amino acid level (Horie et al. 2001). Interestingly, OsHKT2;1 mRNA showed a remarkable accumulation in roots of Nipponbare plants in response to the deprivation of $\mathrm{K}^{+}$for which OsHKT2;1 shows extremely poor permeability (Horie et al. 2001). Moreover, the $\mathrm{K}^{+}$deprivation-induced accumulation of OsHKT2;1 mRNA was significantly suppressed upon the addition of $30 \mathrm{mM} \mathrm{NaCl}$ (Horie et al. 2001). Accumulations of OsHKT2;1 and OsHKT2;2 mRNA in Pokkali were also shown to be regulated in a similar manner in response to various $\mathrm{Na}^{+} / \mathrm{K}^{+}$ conditions as in the case with OsHKT2;1 in Nipponbare (Horie et al. 2001). Reductions of OSHKT2;1 transcripts in response to $150 \mathrm{mM} \mathrm{NaCl}$ in indica cultivars were also reported by Golldack et al. (2002). These analyses suggested that $\mathrm{Na}^{+}$transport through OSHKT2;1 and OsHKT2;2 in rice are closely controlled by $\mathrm{K}^{+}$status in $\mathrm{K}^{+}$-starved rice plants and that the expression is controlled by available levels of $\mathrm{K}^{+}$and $\mathrm{Na}^{+}$(Horie et al. 2001). It has long been known in classical plant physiological studies that acquisition and maintenance of $\mathrm{K}^{+}$during salt stress is important for plant salt tolerance (Flowers and Läuchli, 1983 and references there in). Characterization of the salt overly sensitive $1(\operatorname{sos} l)$ mutant of $A$. thaliana further supported that high-affinity $\mathrm{K}^{+}$uptake under salinity stress is a crucial factor to maintain resistance (Wu et al. 1996). Garciabeblás et al. (2003) found in databases of japonica Nipponbare and indica ssp. that the OsHKT2;2 gene in these varieties is a pseudogene and includes insertion of a $3.1 \mathrm{~kb}$ fragment of "junk" DNA sequence. Kader et al. (2006) have reported that the accumulation of OsHKT2;2 mRNA is increased in response to salt stress in Pokkali but not in the salt sensitive variety BRRI Dhan29. It is still an open question whether the function of OsHKT2;2 could be related to the salt tolerant phenotype of Pokkali plants.

\section{A major role for defined HKT transporters in protecting leaves from sodium damage}

TaHKT2;1 homologs have been characterized or identified in many other plant species such as Arabidopsis, eucalyptus, ice plant, barley, poplar, reed and Suaeda (Fairbairn et al. 2000; Uozumi et al. 2000; Su et al. 2003; Haro et al. 2005; Gierth and Mäser, 2007). AtHKT1;1 in A. thaliana has been shown to mediate $\mathrm{Na}^{+}$selective transport in yeast and Xenopus oocytes (Uozumi et al. 2000). AtHKT1;1 is expressed in the vasculature of $A$. thaliana (Mäser et al. 2002a). AtHKT1;1-mediated $\mathrm{Na}^{+}$ selective transport was later found to play an essential role in the protective mechanism against salinity stress in A. thaliana plants (Mäser et al. 2002a; Berthomieu et al. 2003; Gong et al. 2004; Sunarpi et al. 2005; Horie et al. 2006). Detailed protein localization analyses of McHKT1;1 and AtHKT1;1 showed that they are expressed in the plasma membrane of xylem parenchyma cells ( $\mathrm{Su}$ et al. 2003; Sunarpi et al. 2005). Promoterreporter gene analyses also showed the close rice homologue OsHKT1;5 (SKC1) and AtHKT1;1 expression in xylem parenchyma cells (Ren et al. 2005; Sunarpi et al. 2005). Furthermore, data showed that the $A$. thaliana AtHKT1;1 transporter and OsHKT1;5 function in removing $\mathrm{Na}^{+}$from the xylem sap of plants, thus counteracting $\mathrm{Na}^{+}$over-accumulation in leaves (Ren et al. 2005; Sunarpi et al. 2005; Horie et al. 2006). The model for the function of these HKT isoforms resulting from these studies is that under $\mathrm{Na}^{+}$stress conditions $\mathrm{Na}^{+}$levels increase in the xylem sap (Ren et al. 2005; Sunarpi et al. 2005; Horie et al. 2006). The AtHKT1;1 and OsHKT1;5 transporters can then remove $\mathrm{Na}^{+}$ from the xylem sap (Ren et al. 2005; Sunarpi et al. 2005; Horie et al. 2006), thus prohibiting the overaccumulation of $\mathrm{Na}^{+}$in leaves (Mäser et al. 2002a; Berthomieu et al. 2003; Sunarpi et al. 2005), indicating that in wildtype plants the $\mathrm{Na}^{+}$removed from the xylem sap can be re-circulated by the phloem. Thus these studies have described a mechanism by which expression of defined HKT transporters in rice and Arabidopsis in the xylem parenchyma protects leaves from $\mathrm{Na}^{+}$damage. As the photosynthetic machinery in leaves is particularly sensitive to and damaged by elevated $\mathrm{Na}^{+}$levels (e.g. Horie et al. 2006), these HKT transporters provide an important mechanism mediating $\mathrm{Na}^{+}$tolerance.

\section{Structure of the $\mathrm{K}^{+}$channel-like selectivity filter in the HKT-type transporters/channels determines the $\mathrm{K}^{+} / \mathrm{Na}^{+}$selectivity}

Interestingly, HKT-type transporters/channels can roughly be divided into two different groups based on the $\mathrm{K}^{+}$selectivity in heterologous expression systems. Ion selectivity analyses of TaHKT2;1 and AtHKT1;1-chimera constructs in yeast and Xenopus oocytes have led to the identification of an important region in the $\mathrm{N}$-terminus of TaHKT2;1, that functions in modulating $\mathrm{K}^{+}$selectivity (Mäser et al. 2002b). The region was found to contain a putative pore-forming region called "P-loop" that is distantly homologous to that of the bacterial $\mathrm{K}^{+}$channel, KcsA (Durell and Guy, 1999; Durell et al. 1999; Mäser et al. 2002b). The alignment of the P-loop regions of HKT, bacterial transporters, Trk and KtrB, and shaker $\mathrm{K}^{+}$channel of Drosophila showed that the critical amino acid that determined $\mathrm{K}^{+}$permeability in the above chimeras corresponded to a glycine residue in the P- 
loop, which corresponds to the first glycine of the GYG motif that is highly conserved among $\mathrm{K}^{+}$channels for $\mathrm{K}^{+}$selectivity (Mäser et al. 2002b). Interestingly, the glycine residue was conserved in $\mathrm{K}^{+}$permeable HKTs such as TaHKT2;1 and OsHKT2;2. However, this amino acid position was serine instead of glycine in $\mathrm{Na}^{+}$ selective HKTs such as AtHKT1;1 and OsHKT2;1 (Horie et al. 2001; Mäser et al. 2002b). HKT and its homologous transporters, Trk and KtrB, have been found to include four P-loop regions in their amino acid sequences (Durell and Guy, 1999; Durell et al. 1999). Glycine residues in the other three P-loops of HKT/Trk/KtrB transporters/channels were completely conserved, independently of the ion selectivity. These data showed that $\mathrm{K}^{+}$permeable HKT transporters analyzed have a G-G-G-G motif in the four P-loops, whereas the HKTs showing more $\mathrm{Na}^{+}$selective $\mathrm{Na}^{+}$ transport have a S-G-G-G motif in the P-loops. Note that $\mathrm{Na}^{+}$"selective" in biology is always a relative term, as other related cations usually show some degree of relative permeability. Site direct mutagenesis was performed on TaHKT2;1, AtHKT1;1, OsHKT2;1 and OsHKT2;2 cDNAs, which converted the glycine to serine (TaHKT2;1 and OsHKT2;2) or the serine to glycine (AtHKT1;1 and OsHKT2;1) in the first P-loop region (Mäser et al. 2002b). The substitutions of the glycine to serine in TaHKT2;1 and OsHKT2;2 did not remove $\mathrm{Na}^{+}$transport activity but impaired their $\mathrm{K}^{+}$ permeability in heterologous expression systems with yeast (Saccharomyces cerevisiae) (Mäser et al. 2002b) (Fig. 1). On the other hand, the substitutions of the serine to glycine conferred $\mathrm{K}^{+}$permeability to AtHKT1;1 and OsHKT2;1 leaving their $\mathrm{Na}^{+}$transport activity in heterologous expression systems (Mäser et al. 2002b) (Fig. 1). Consistent results were found in the analyses of $\mathrm{Na}^{+}$-dependent $\mathrm{K}^{+}$transporter $\mathrm{KtrAB}$ complex by mutating all four glycine residues in the four $\mathrm{p}$-loops of this bacterial $\mathrm{K}^{+}$transporter (Tholema et al. 2005). This study showed that the presence of the glycine residue in each of the four $\mathrm{p}$-loops is essential for $\mathrm{K}^{+}-\mathrm{Na}^{+}$cotransport of the wildtype $\mathrm{K} \operatorname{tr} \mathrm{AB}$ transporter, whereas mutations of these glycines led to isoforms with reduced $\mathrm{K}^{+}$transport and enhanced $\mathrm{Na}^{+}$transport (Tholema et al. 2005). Taken together, these studies demonstrated that the conserved glycine residue in the first P-loop region of the $\mathrm{HKT} / \mathrm{Trk} / \mathrm{KtrB}$ family is essential for $\mathrm{K}^{+}$ permeability, and that the $\mathrm{HKT} / \mathrm{Trk} / \mathrm{K} \operatorname{trB}$ family retains similar structures of the selectivity filter, which seem to be related to those of $\mathrm{K}^{+}$channels (Mäser et al. 2002b).

\section{$\mathrm{K}^{+} / \mathrm{Na}^{+}$selectivity of OsHKT proteins}

We found that the expression of the G-G-G-G type mutant of OsHKT2;1 (OsHKT2;1- S88G) rendered salt sensitive yeast cells (G19 strain of $S$. cerevisiae) far less

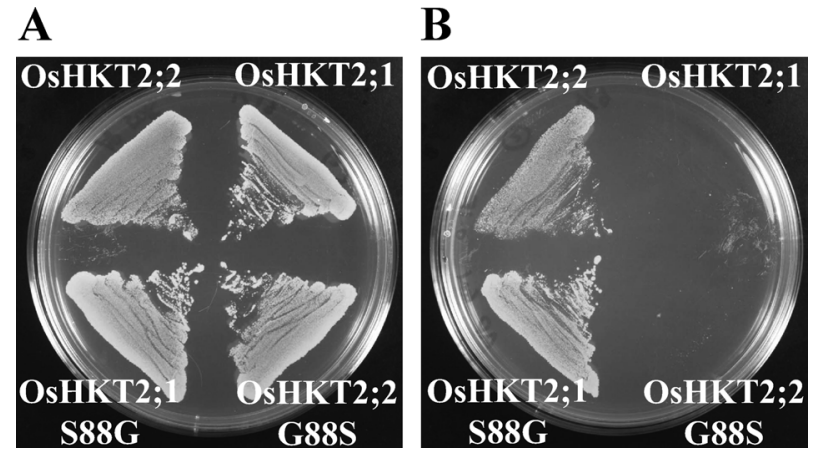

Figure 1. Conserved glycine residue in the first P-loop region is essential for $\mathrm{K}^{+}$permeability of HKT proteins (Mäser et al. 2002b; Copyright 2002 National Academy of Sciences, U.S.A.). Expression of OsHKT2;1 does not rescue the growth defect of high-affinity $\mathrm{K}^{+}$ uptake deficient mutant (trk1, trk2) of Saccharomyces cerevisiae, CY162 strain, under a low $\mathrm{K}^{+}$condition, but in contrast, OsHKT2;2 does. Mutations of ser-88 to glycine in OsHKT2;1 (OsHKT2;1 S88G) and gly-88 to serine in OsHKT2;2 (OsHKT2;2 G88S) converted their $\mathrm{K}^{+}$permeability in the mutant cells. (A) CY162 cells expressing either OsHKT2;1, OsHKT2;2, OsHKT2;1 S88G, or OsHKT2;2 G88S on the arginine phosphate (AP) medium containing $50 \mathrm{mM} \mathrm{KCl}$. (B) Same CY162 cells as in A, growing on the AP medium containing $0.1 \mathrm{mM}$ $\mathrm{KCl}$.

sensitive to $\mathrm{Na}^{+}$under various $\mathrm{NaCl}$ stress conditions presumably due to improved $\mathrm{K}^{+}$transport and reduced toxic $\mathrm{Na}^{+}$influx (data not shown). $\mathrm{K}^{+} / \mathrm{Na}^{+}$selectivity of three kinds of OsHKT proteins, OsHKT2;1, OsHKT2;2 and OsHKT2;1-S88G, was comparatively evaluated with using a yeast assay system. We expressed each $O S H K T$ cDNA under the yeast GAL1 promoter, and introduced the chimera constructs into yeast W303 strain that retains high-affinity $\mathrm{K}^{+}$uptake system encoded by the TRK1 and TRK2 genes, since we also intended to test whether the OsHKT2;1-S88G protein could ameliorate salt tolerance of wildtype cells as a model case toward molecular breeding of salt tolerance making use of OsHKT proteins. All transgenic yeast cells grew normally in the low potassium $\left(0.1 \mathrm{mM} \mathrm{K}^{+}\right)$and low sodium $(25 \mu \mathrm{M})$ condition. $100 \mathrm{mM}$ of $\mathrm{Na}^{+}$decreased the growth of yeast cells expressing OsHKT2;1 or OsHKT2;2 by approximately $57 \%$, however, this growth inhibition was about $12 \%$ in the case of yeast cells producing OsHKT2;1-S88G (data not shown). These results suggest that $\mathrm{Na}^{+}$transport activity of OsHKT2;1S88G is weaker than OsHKT2;1 and OsHKT2;2 in the presence of excessive $\mathrm{Na}^{+}$. To confirm this, intracellular $\mathrm{K}^{+}$and $\mathrm{Na}^{+}$contents in yeast were measured with the inductively coupled plasma optical emission spectrometry (ICP-OES). $\mathrm{Na}^{+} / \mathrm{K}^{+}$ratios in cells expressing OsHKT2;1 and OsHKT2;2 were much higher than ratios in cells expressing OsHKT2;1-S88G in the presence of 100 or $300 \mathrm{mM}$ of $\mathrm{Na}^{+}$(Fig. 2). However, these results are not sufficient to discuss about enhancement of salt tolerance by OsHKT2;1-S88G in yeast cells. Finding mutations which further reduce $\mathrm{Na}^{+}$transport of the OsHKT2;1- 


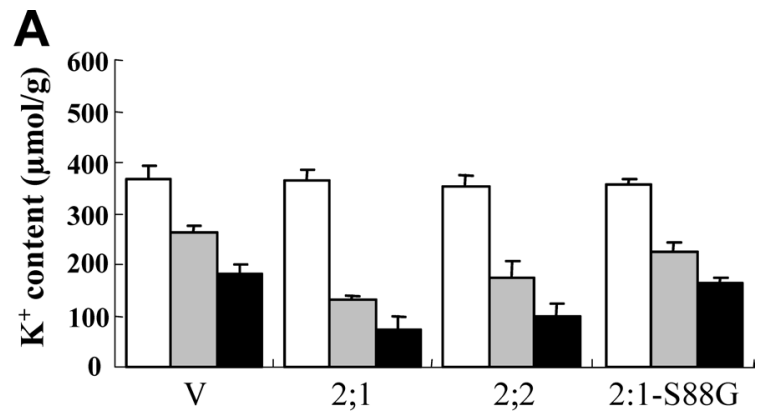

B
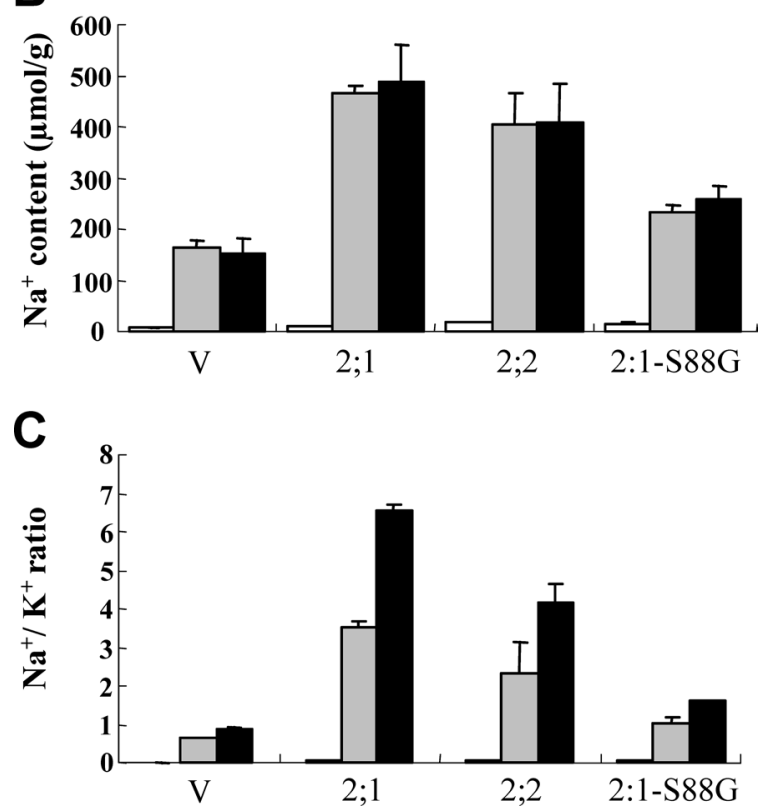

Figure 2. Intracellular $\mathrm{K}^{+}$and $\mathrm{Na}^{+}$accumulation of yeast cells expressing OsHKT genes. Strain W303 of S. cerevisiae (MATa, trp1, leu2, ade2, ura3, his3, lys2, can1) was used as host cells. Yeast was grown in $\mathrm{AP}$ medium supplemented with no $\mathrm{NaCl}$ (open bar), $100 \mathrm{mM}$ $\mathrm{NaCl}$ (grey bar) or $300 \mathrm{mM} \mathrm{NaCl}$ (filled bar). $\mathrm{K}^{+}$content (A) and $\mathrm{Na}^{+}$ content (B) of yeast expressing each $O s H K T$ gene $(2 ; 1,2 ; 2$ and 2;1$\mathrm{S} 88 \mathrm{G})$ or vector $(\mathrm{V})$ was measured with ICP-OES (IRIS Intrepid II, Thermo Fisher Scientific, USA). $\mathrm{Na}^{+} / \mathrm{K}^{+}$ratio is calculated based on data of $\mathrm{K}^{+}$and $\mathrm{Na}^{+}$contents $(\mathrm{C})$. Error bars represent $\pm \mathrm{SD}(n=3)$.

S88G protein leaving its $\mathrm{K}^{+}$transport property as it is in high $\mathrm{Na}^{+}$concentrations could provide an ideal tool for future molecular breeding of salt tolerant plants.

\section{OsHKT2;1 mediates "nutritional $\mathrm{Na}^{+}$ absorption and distribution" in $\mathrm{K}^{+}$-starved rice plants: role of $\mathrm{Na}^{+}$as a substitute nutrient for $\mathrm{K}^{+}$}

OsHKT2;1 was well-characterized as a $\mathrm{Na}^{+}$selective transporter/channel using heterologous expression systems (Horie et al. 2001; Garciabeblás et al. 2003). However, the physiological role of OsHKT2;1 in planta remained to be elucidated until recently. Horie et al. (2007) found Tos17-insertion mutants, which are disrupted in the OsHKT2; 1 gene of Nipponbare plants. Tos 17 is an endogenous retrotransposon in rice plants, which undergoes local transposition events only during tissue culture, and thus is an ideal mutagen (Hirochika, 1997, 2001; Miyao et al. 2003). Three independent oshkt2;1 knock out mutant alleles were isolated and grown under various $\mathrm{Na}^{+}$conditions to search for physiological and stress phenotypes. Interestingly, all oshkt2;1 mutant plants were found to show remarkably meager growth under

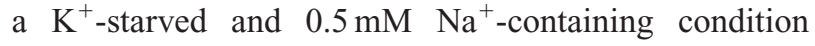
compared to wildtype (WT) plants (Horie et al. 2007) (Fig. 3). oshkt2;1 mutants were also shown to accumulate much less $\mathrm{Na}^{+}$in shoots, roots and the xylem compared to WT plants (Horie et al. 2007). Furthermore, tracer influx experiments using ${ }^{22} \mathrm{NaCl}$ and oshkt2;1 mutant and WT plants indicated that: (i) OsHKT2;1 directly mediates $\mathrm{Na}^{+}$influx into roots of $\mathrm{K}^{+}$-starved rice plants; (ii) OsHKT2;1-dependent $\mathrm{Na}^{+}$influx is detected only in $\mathrm{K}^{+}$-starved roots (not with $\mathrm{K}^{+}$-supplied roots); (iii) Approximately 80 to $90 \%$ of $\mathrm{Na}^{+}$influx into intact $\mathrm{K}^{+}$starved rice roots is mediated by OsHKT2;1-dependent $\mathrm{Na}^{+}$influx at low $\mathrm{Na}^{+}$concentrations (1 to $200 \mu \mathrm{M}$ ); and (iv) OsHKT2;1 robustly mediates $\mathrm{Na}^{+}$influx at low millimolar $\mathrm{Na}^{+}$concentrations, although the relative contribution of OsHKT2;1 to $\mathrm{Na}^{+}$influx to whole root $\mathrm{Na}^{+}$influx is reduced at an increase in the $\mathrm{Na}^{+}$ concentration, presumably because of the effect of the other $\mathrm{Na}^{+}$permeable transporters/channels working at higher $\mathrm{Na}^{+}$concentrations in rice roots (Horie et al. 2007). Furthermore, whereas oshkt2;1 knock out mutations dramatically reduced $\mathrm{Na}^{+}$influx into roots, $\mathrm{Rb}^{+}$influx was not greatly affected (Horie et al. 2007), consistent with the high $\mathrm{Na}^{+}$to $\mathrm{K}^{+}$selectivity of OsHKT2;1 measured in heterologous systems (Horie et al. 2001).

The above results demonstrated that $\mathrm{Na}^{+}$, which is not an essential nutrient for plant growth and causes toxicity when it is excessively accumulated in plants, can substitute for some roles of $\mathrm{K}^{+}$as a substitute nutrient in $\mathrm{K}^{+}$-starved rice plants (Horie et al. 2007). Moreover, the results also clearly demonstrated that the OsHKT2;1 transporter/channel is responsible for the nutritional $\mathrm{Na}^{+}$ uptake into $\mathrm{K}^{+}$-starved roots and distribution throughout $\mathrm{K}^{+}$-starved rice plants (Horie et al. 2007) (Fig. 4A). Classical plant physiological studies have pointed out that $\mathrm{Na}^{+}$behaves as a substitute nutrient for $\mathrm{K}^{+}$under $\mathrm{K}^{+}$-starvation in some plants (Mengel and Kirkby 1982; Flowers and Läuchli 1983 and references there in). The report of Horie et al. (2007) provides robust genetic evidence that $\mathrm{Na}^{+}$indeed substitutes for some roles of $\mathrm{K}^{+}$, and that the gene causing this phenomenon is the OsHKT2;1-type gene in planta. It should be mentioned that not every plant species shows positive effects upon the addition of $\mathrm{Na}^{+}$under $\mathrm{K}^{+}$-starved conditions, and that plants seem to be categorized into four groups, depending on the response when $\mathrm{Na}^{+}$is added (Flowers 

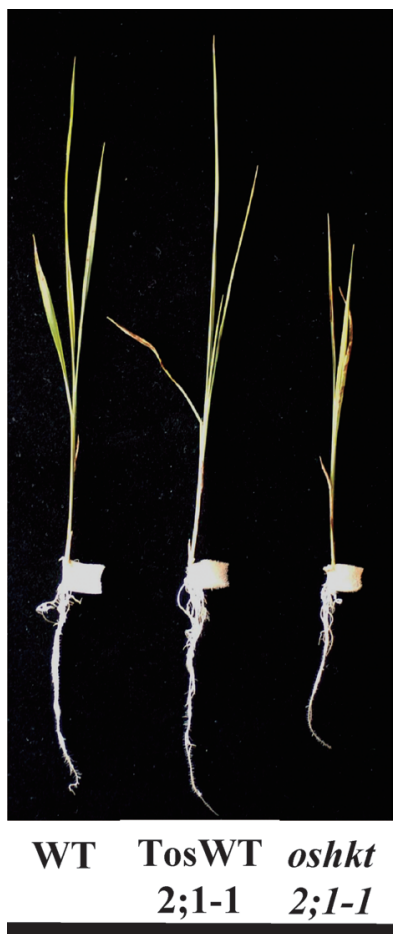

Figure 3. oshkt2;1 mutant plants show significant growth defect when a moderate amount of $\mathrm{Na}^{+}$exists in $\mathrm{K}^{+}$starved condition. An example of growth assays using oshkt2;1-1 allele, which is one of three oshkt2;1 mutant alleles reported in Horie et al. (2007). Ten-day old $\mathrm{K}^{+}$-starved plants were transferred onto hydroponic solution which contains no $\mathrm{K}^{+}$and $0.5 \mathrm{mM} \mathrm{Na}^{+}$. The picture was taken 15 days later. Note that TosWT2;11 represents corresponding wildtype plants, which were isolated from the same parent plants as oshkt2;1-1.
A
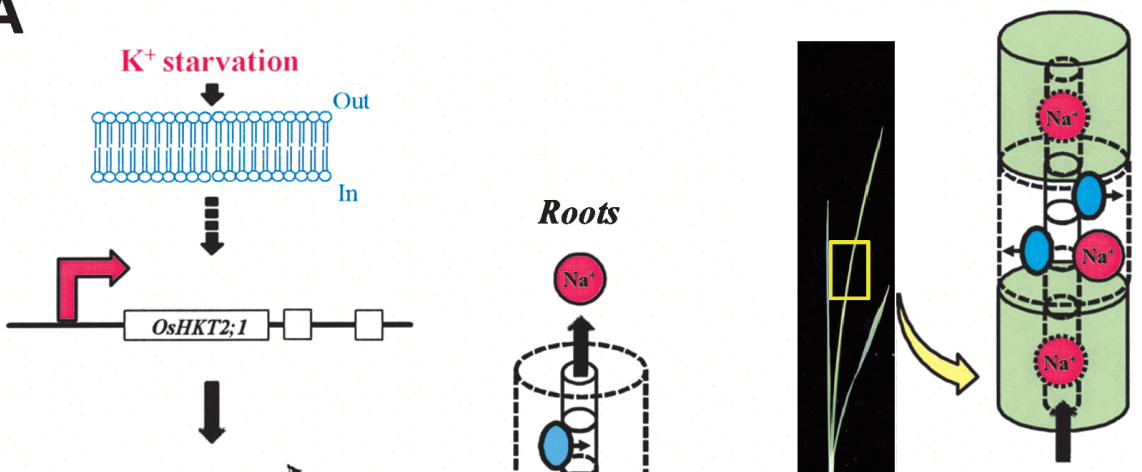

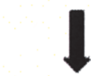
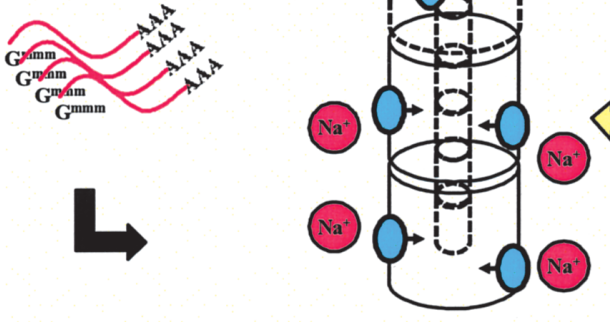

Shoots

B
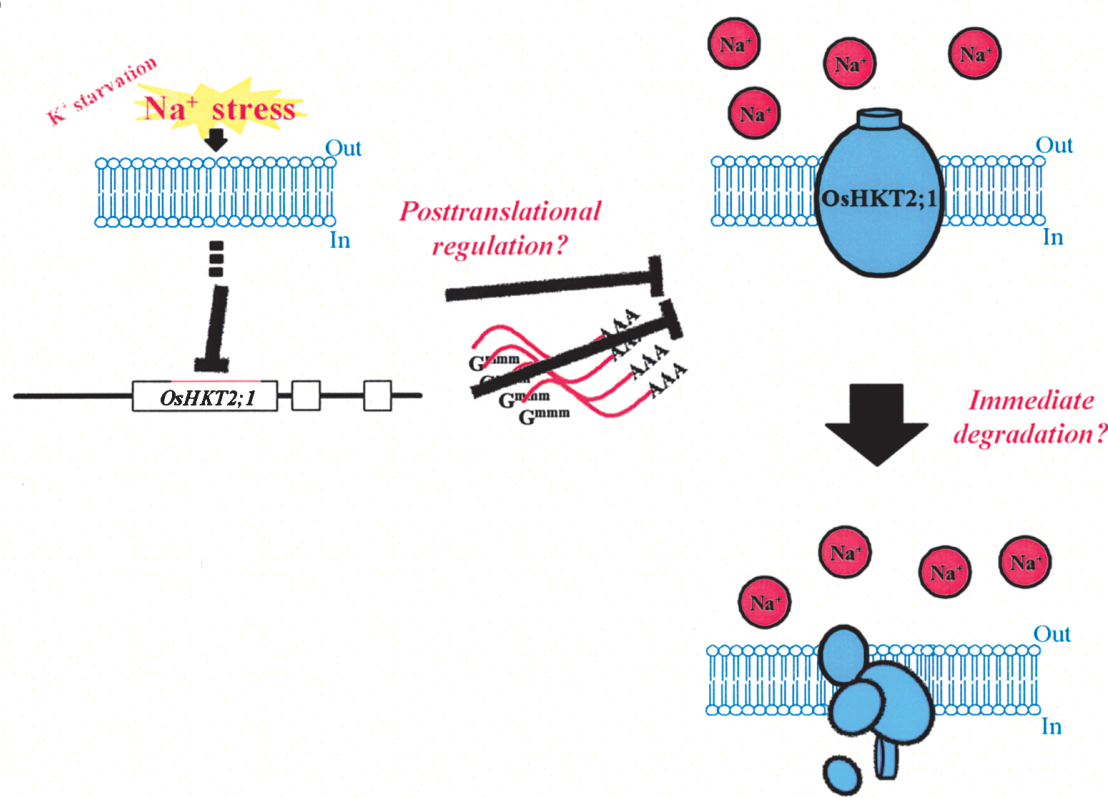

Figure 4. Models of the function of OsHKT2;1 in nutritional $\mathrm{Na}^{+}$uptake and rapid repression of OsHKT2;1 in the presence of a large amount of $\mathrm{Na}^{+}$. (A) Transcription of the OsHKT2;1 gene is activated in response to $\mathrm{K}^{+}$starvation. OsHKT2;1 functions in $\mathrm{Na}^{+}$absorption and distribution in $\mathrm{K}^{+}$starved rice plants for growth. (B) OsHKT2;1-dependent $\mathrm{Na}^{+}$influx is rapidly down-regulated in response to high concentrations of $\mathrm{Na}^{+}$by means of transcriptional and most likely rapid posttranslational regulation mechanisms (Horie et al. 2007). and Läuchli, 1983).

OsHKT2;1 has been shown to mediate large $\mathrm{Na}^{+}$ influx into cells with a $\mathrm{Na}^{+}$channel-like feature in heterologous expression systems (Horie et al. 2001), which could lead to the hypothesis that OsHKT2;1 mediates toxic $\mathrm{Na}^{+}$influx under saline conditions. However, oshkt2;1 mutant plants did not show any difference under salt stress compared to WT plants
(Horie et al. 2007). Interestingly, ${ }^{22} \mathrm{NaCl}$ tracer influx experiments indicated that OsHKT2;1-dependent $\mathrm{Na}^{+}$ influx is rapidly down-regulated by the addition of $30 \mathrm{mM} \mathrm{NaCl}$ on $\mathrm{K}^{+}$-starved roots (Horie et al. 2007). These results suggest that OsHKT2;1-dependent $\mathrm{Na}^{+}$ influx in $\mathrm{K}^{+}$-starved roots is tightly regulated to prevent $\mathrm{Na}^{+}$toxicity due to mass flow of $\mathrm{Na}^{+}$via OsHKT2;1 (Figure 4B). Elucidating the molecular mechanism that 
posttranslationally controls the activity of OsHKT2;1 could provide important clues and hints for developing new technology toward future molecular breeding of salt tolerant plants.

\section{Roles for other plant HKT transporters}

The HKT-type transporter/channel is one of the most studied $\mathrm{Na}^{+}$permeable proteins in plants (Horie and Schroeder 2004). Nine OsHKT genes including OsHKT2; 1 have been identified on the genome of Nipponbare plants and two of them were further found to be pseudogenes, suggesting that 7 full-length $O s H K T$ genes are expressed in Nipponbare plants (Garciabeblás et al. 2003). It is worth paying attention to the fact that oshkt2;1 mutant plants showed strong phenotypes in nutritional $\mathrm{Na}^{+}$absorption and distribution nevertheless the other 6 OsHKT genes are functional. The OsHKT2;1 gene may be a specific gene evolved to maintain alkali metal cation homeostasis of rice plants under poor soil conditions (Horie et al. 2007; Mueller-Roeber and Dreyer 2007). Among 6 other OsHKT genes, OsHKT1;4 and OsHKT1;5 (SKC1) are close homologs of AtHKT1;1 which is essential for salt tolerance of $A$. thaliana plants. Furthermore, from rough mapping studies, HKT1;4 and $H K T 1 ; 5$ alleles of durum wheat were reported as putative candidates genes in the mapping regions conferring salt tolerance to wheat plants (Huang et al. 2006; Byrt et al. 2007). These wheat genes are also the closest homologs to AtHKT1;1 and thus appear to have an orthologous function to that characterized in A. thaliana. We do not yet have any evidence for the physiological roles of OsHKT1;1, 1;3, 2;3 and 2;4 transporters in rice plants. Investigating their roles will be important future inquiries to figure out the complete mechanism of $\mathrm{Na}^{+}$ homeostasis through OsHKT proteins in rice plants.

\section{Conclusions}

Salt stress is one of the most relevant abiotic stresses reducing agricultural productivity. Soil salinity is expanding in irrigated lands, which is a serious threat to agriculture. HKT-type transporters/channels have been shown to play essential roles in $\mathrm{Na}^{+}$homeostasis in plants, such as salinity resistance and growth under $\mathrm{K}^{+}$starved conditions. Elucidating roles of $\mathrm{Na}^{+}$permeable transporters/channels including HKT proteins in salinity resistance is an essential subject to address. Global climate change and its potential impact on food production may threaten life of mankind. The necessity to elucidate the whole picture of resistance mechanisms to abiotic and biotic stresses in plants and to develop technology for producing stress resistant plants is of great relevance for agriculture in the 21 st century.

\section{Acknowledgements}

We are grateful to Mr. Koichiro Taira of the Nara Prefectural Agricultural Experiment Station for instruction and technical helps on ICP-OES analysis. A part of research about OsHKTs and AtHKT was supported by a Grant-in-Aid for scientific research to K.Y. and Global COE Program in NAIST "Frontier Biosciences" from the Ministry of Education, Culture, Sports, Science, and Technology of Japan and by a Department of Energy grant (DOEDE-FG02-03ER15449) to J.I.S.

\section{References}

Anderson JA, Huprikar SS, Kochian LV, Lucas WJ, Gaber RF (1992) Functional expression of a probable Arabidopsis thaliana potassium channel in Saccharomyces cerevisiae. Proc Natl Acad Sci USA 89: 3736-3740

Berthomieu P, Conejero G, Nublat A, Brackenbury WJ, Lambert C, Savio C, Uozumi N, Oiki S, Yamada K, Cellier F, Gosti F, Simonneau T, Essah PA, Tester M, Very AA, Sentenac H, Casse F (2003) Functional analysis of AtHKT1 in Arabidopsis shows that $\mathrm{Na}^{+}$recirculation by the phloem is crucial for salt tolerance. EMBO J 22: 2004-2014

Byrt CS, Platten JD, Spielmeyer W, James RA, Lagudah ES, Dennis ES, Tester M, Munns R (2007) HKT1;5-like Cation Transporters Linked to $\mathrm{Na}^{+}$Exclusion Loci in Wheat, Nax2 and Kna1. Plant Physiol 143: 1918-1928

Durell SR, Guy HR (1999) Structural models of the KtrB, TrkH, and Trk1,2 symporters based on the structure of the KcsA $\mathrm{K}^{+}$ channel. Biophys J77: 789-807

Durell SR, Hao Y, Nakamura T, Bakker EP, Guy HR (1999) Evolutionary relationship between $\mathrm{K}^{+}$channels and symporters. Biophys J 77: 775-788

Fairbairn DJ, Liu W, Schachtman DP, Gomez-Gallego S, Day SR, Teasdale RD (2000) Characterization of two distinct HKT1-like potassium transporters from Eucalyptus camaldulensis. Plant Mol Biol 43: 515-525

Flowers TJ, Läuchli A (1983) Sodium versus potassium: Substitution and compartmentation. Inorganic Plant Nutrition 15b: 651-681

Fu HH, Luan S (1998) AtKuP1: a dual-affinity $\mathrm{K}^{+}$transporter from Arabidopsis. Plant Cell 10: 63-73

Garciadeblás B, Senn ME, Bañuelos MA, Rodríguez-Navarro A (2003) Sodium transport and HKT transporters: the rice model. Plant J 34: 788-801

Gassmann W, Rubio F, Schroeder JI (1996) Alkali cation selectivity of the wheat root high-affinity potassium transporter HKT1. Plant $J$ 10: 869-852

Gierth M, Mäser P (2007) Potassium transporters in plantsinvolvement in $\mathrm{K}^{+}$acquisition, redistribution and homeostasis. FEBS Lett 581: 2348-2356

Gierth M, Mäser P, Schroeder JI (2005) The potassium transporter AtHAK5 functions in $\mathrm{K}^{+}$deprivation-induced high-affinity $\mathrm{K}^{+}$ uptake and $\mathrm{AKT} 1 \mathrm{~K}^{+}$channel contribution to $\mathrm{K}^{+}$uptake kinetics in Arabidopsis roots. Plant Physiol 137: 1105-1114

Golldack D, Su H, Quigley F, Kamasani UR, Munoz-Garay C, Balderas E, Popova OV, Bennett J, Bohnert HJ, Pantoja O (2002) Characterization of a HKT-type transporter in rice as a general alkali cation transporter. Plant J 31: 529-542

Gong JM, Waner DA, Horie T, Li SL, Horie R, Abid KB, Schroeder JI (2004) Microarray-based rapid cloning of an ion 
accumulation deletion mutant in Arabidopsis thaliana. Proc Natl Acad Sci USA 101: 15404-15409

Haro R, Bañuelos MA, Senn ME, Barrero-Gil J, RodríguezNavarro A (2005) HKT1 mediates sodium uniport in roots. Pitfalls in the expression of HKT1 in yeast. Plant Physiol 139: 1495-1506

Hirochika H (1997) Retrotransposons of rice: their regulation and use for genome analysis. Plant Mol Biol 35: 231-240

Hirochika H (2001) Contribution of the Tos 17 retrotransposon to rice functional genomics. Curr Opin Plant Biol 4: 118-122

Hirsch RE, Lewis BD, Spalding EP, Sussman MR (1998) A role for the AKT1 potassium channel in plant nutrition. Science 280: 918-921

Horie T, Costa A, Kim TH, Han MJ, Horie R, Leung HY, Miyao A, Hirochika H, An G, Schroeder JI (2007) Rice OsHKT2;1 transporter mediates large $\mathrm{Na}^{+}$influx component into $\mathrm{K}^{+}$starved roots for growth. EMBO J 26: 3003-3014

Horie T, Horie R, Chan WY, Leung HY, Schroeder JI (2006) Calcium regulation of sodium hypersensitivities of $\operatorname{sos} 3$ and athkt1 mutants. Plant Cell Physiol 47: 622-633

Horie T, Schroeder JI (2004) Sodium transporters in plants. Diverse genes and physiological functions. Plant Physiol 136: 2457-2462

Horie T, Yoshida K, Nakayama H, Yamada K, Oiki S, Shinmyo A (2001) Two types of HKT transporters with different properties of $\mathrm{Na}^{+}$and $\mathrm{K}^{+}$transport in Oryza sativa. Plant J 27: 129-138

Huang S, Spielmeyer W, Lagudah ES, James RA, Platten JD, Dennis ES, Munns R (2006) A sodium transporter (HKT7) is a candidate for Naxl, a gene for salt tolerance in durum wheat. Plant Physiol 142: 1718-1727

Kader MA, Seidel T, Golldack, D and Lindberg S (2006) Expression of OsHKT1, OsHKT2, and OsVHA are differentially regulated under $\mathrm{NaCl}$ stress in salt-sensitive and salt-tolerant rice (Oryza sativa L.) cultivars. J Exp Bot 15: 4257-4268

Kim EJ, Kwak JM, Uozumi N, Schroeder JI (1998) AtKUPI: an Arabidopsis gene encoding high-affinity potassium transport activity. Plant Cell 10: 51-62

Mäser P, Eckelman B, Vaidyanathan R, Horie T, Fairbairn DJ, Kubo M, Yamagami M, Yamaguchi K, Nishimura M, Uozumi N, Robertson W, Sussman MR, Schroeder JI (2002a) Altered shoot/root $\mathrm{Na}^{+}$distribution and bifurcating salt sensitivity in Arabidopsis by genetic disruption of the $\mathrm{Na}^{+}$transporter AtHKT1. FEBS Lett 531: 157-161

Mäser P, Hosoo Y, Goshima S, Horie T, Eckelman B, Yamada K, Yoshida K, Bakker EP, Shinmyo A, Oiki S, Schroeder JI, Uozumi N (2002b) Glycine residues in potassium channel-like selectivity filters determine potassium selectivity in four-loopper-subunit HKT transporters from plants. Proc Natl Acad Sci USA 99: 6428-6433

Mengel K, Kirkby EA (1982) Principles of Plant Nutrition, Ed3. International Potash Institute, Worblaufen-Bern, Switzerland: 425-426

Miyao A, Tanaka K, Murata K, Sawaki H, Takeda S, Abe K,
Shinozuka Y, Onosato K, Hirochika H (2003) Target site specificity of the Tos 17 retrotransposon shows a preference for insertion within genes and against insertion in retrotransposonrich regions of the genome. Plant Cell 15: 1771-1780

Mueller-Roeber B, Dreyer I (2007) Ion homeostasis: plants feel better with proper control. EMBO Rep 8: 735-736

Platten JD, Cotsaftis O, Berthomieu P, Bohnert H, Davenport RJ, Fairbairn DJ, Horie T, Leigh RA, Lin HX, Luan S, Mäser P, Pantoja O, Rodríguez-Navarro A, Schachtman DP, Schroeder JI, Sentenac H, Uozumi N, Very AA, Zhu JK, Dennis ES, Tester M (2006) Nomenclature for HKT transporters, key determinants of plant salinity tolerance. Trends Plant Sci 11: 372-374

Ren ZH, Gao JP, Li LG, Cai XL, Huang W, Chao DY, Zhu MZ, Wang ZY, Luan S, Lin HX (2005) A rice quantitative trait locus for salt tolerance encodes a sodium transporter. Nat Genet 37 : $1141-1146$

Rubio F, Gassmann W, Schroeder JI (1995) Sodium-driven potassium uptake by the plant potassium transporter HKT1 and mutations conferring salt tolerance. Science 270: 1660-1663

Santa-María GE, Rubio F, Dubcovsky J, Rodríguez-Navarro A (1997) The HAKl gene of barley is a member of a large gene family and encodes a high-affinity potassium transporter. Plant Cell 9: 2281-2289

Schachtman DP, Schroeder JI (1994) Structure and transport mechanism of a high-affinity potassium uptake transporter from higher plants. Nature 370: 655-658

Sentenac H, Bonneaud N, Minet M, Lacroute F, Salmon JM, Gaymard F, Grignon C (1992) Cloning and expression in yeast of a plant potassium ion transport system. Science 256: 663-665

Su H, Balderas E, Vera-Estrella R, Golldack D, Quigley F, Zhao C, Pantoja O, Bohnert HJ (2003) Expression of the cation transporter McHKT1 in a halophyte. Plant Mol Biol 52: 967-980

Sunarpi, Horie T, Motoda J, Kubo M, Yang H, Yoda K, Horie R, Chan WY, Leung HY, Hattori K, Konomi M, Osumi M, Yamagami M, Schroeder JI, Uozumi N (2005) Enhanced salt tolerance mediated by AtHKT1 transporter-induced $\mathrm{Na}^{+}$ unloading from xylem vessels to xylem parenchyma cells. Plant J 44: 928-938

Tholema N, Vor der Bruggen M, Mäser P, Nakamura T, Schroeder JI, Kobayashi H, Uozumi N, Bakker EP (2005) All four putative selectivity filter glycine residues in KtrB are essential for high affinity and selective $\mathrm{K}^{+}$uptake by the KtrAB system from Vibrio alginolyticus. J Biol Chem 280: 41146-41154

Uozumi N, Kim EJ, Rubio F, Yamaguchi T, Muto S, Tsuboi A, Bakker EP, Nakamura T, Schroeder JI (2000) The Arabidopsis HKT1 gene homolog mediates inward $\mathrm{Na}^{+}$currents in Xenopus laevis oocytes and $\mathrm{Na}^{+}$uptake in Saccharomyces cerevisiae. Plant Physiol 122: 1249-1259

Wu SJ, Ding L, Zhu JK (1996) SOS1, a genetic locus essential for salt tolerance and potassium acquisition. Plant Cell 8: 617-627 